\title{
Milo : l'acropole (la colline du Prophète Élie) - 2017
}

\section{Alain Badie et Jean-Charles Moretti}

\section{OpenEdition \\ Journals}

Édition électronique

URL : http://journals.openedition.org/baefe/1942

DOI : 10.4000/baefe.1942

ISSN : 2732-687X

Éditeur

ResEFE

\section{Référence électronique}

Alain Badie, Jean-Charles Moretti, « Milo : I'acropole (la colline du Prophète Élie) - 2017 » [notice archéologique], Bulletin archéologique des Écoles françaises à l'étranger [En ligne], Grèce, mis en ligne le 23 décembre 2020, consulté le 22 mars 2021. URL : http://journals.openedition.org/baefe/1942 ; DOI : https://doi.org/10.4000/baefe.1942

Ce document a été généré automatiquement le 22 mars 2021

\section{cc)}

Le Bulletin archéologique des Écoles françaises à l'étranger est mise à disposition selon les termes de la Licence Creative Commons Attribution - Pas d'Utilisation Commerciale - Pas de Modification 4.0 International. 


\title{
Milo : l'acropole (la colline du Prophète Élie) - 2017
}

\author{
Alain Badie et Jean-Charles Moretti
}

\section{NOTE DE L'AUTEUR}

Autorité nationale présente : Éphorie des Cyclades

Numéro de mission : 134

Établissements porteurs de l'opération : EFA

1 À l'invitation de P. Pantou et avec le soutien de l'éphorie des Cyclades, de l'École française d'Athènes et de l'Institut de recherche sur l'architecture antique nous avons poursuivi du 18 au 28 septembre l'étude engagée en 2016 des vestiges antiques situés dans la cité de Milo sur la colline du Prophète Élie. À partir de photogrammétries réalisées en 2016 par L. Fadin et J.-J. Malmary et complétées cette année, nous avons dessiné un plan du site au 1/100 (fig. 1) et achevé le relevé au $1 / 10$ des blocs qui avaient été identifiés l'année dernière. 
Fig. 1. Relevé général du sommet de la Colline du prophète Élie avec situation des blocs antiques. En jaune les blocs de marbre ; en bleu ceux de granit.

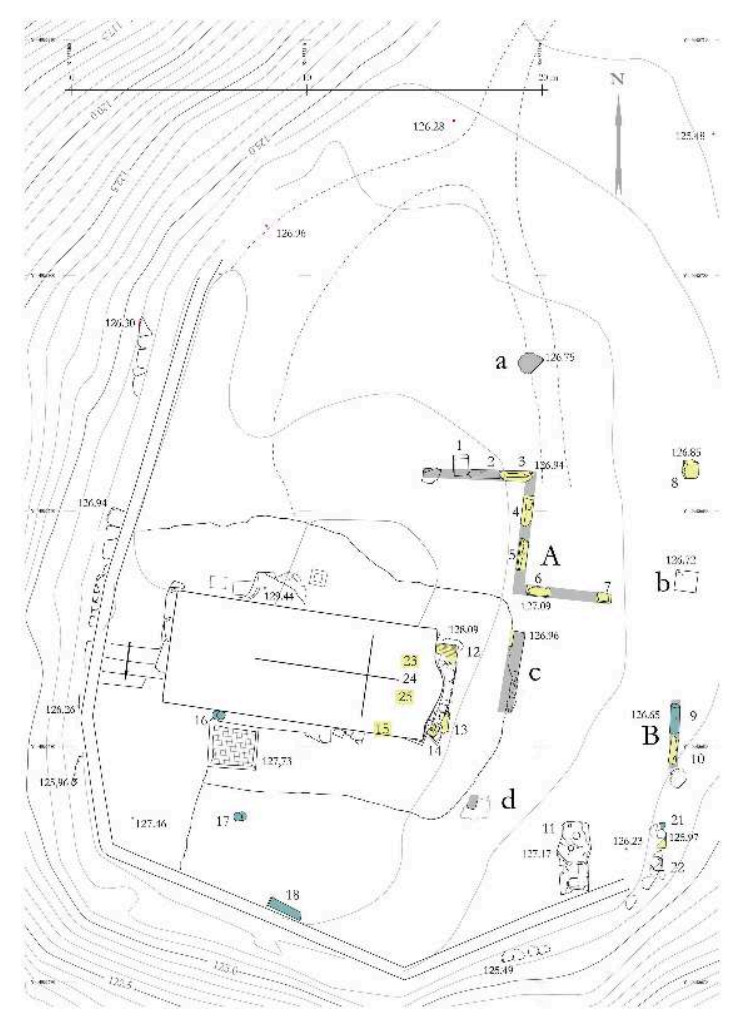

A. Badie, L. Fadin, J.-J. Malmary, J.-Ch. Moretti.

2 Trois nouveaux blocs sont venus s'ajouter à l'inventaire dressé en 2017. Tous trois, remployés dans l'autel maçonné dans l'abside de la chapelle, ont été partiellement dégagés au début de l'année par Y. Staiikopoulos (fig. 2). Nous y avons reconnu : 
Fig. 2. Le fût inv. 23 , la base inv. 24 et le bloc à doucine 25 remployés dans l'autel de l'église du prophète Élie.

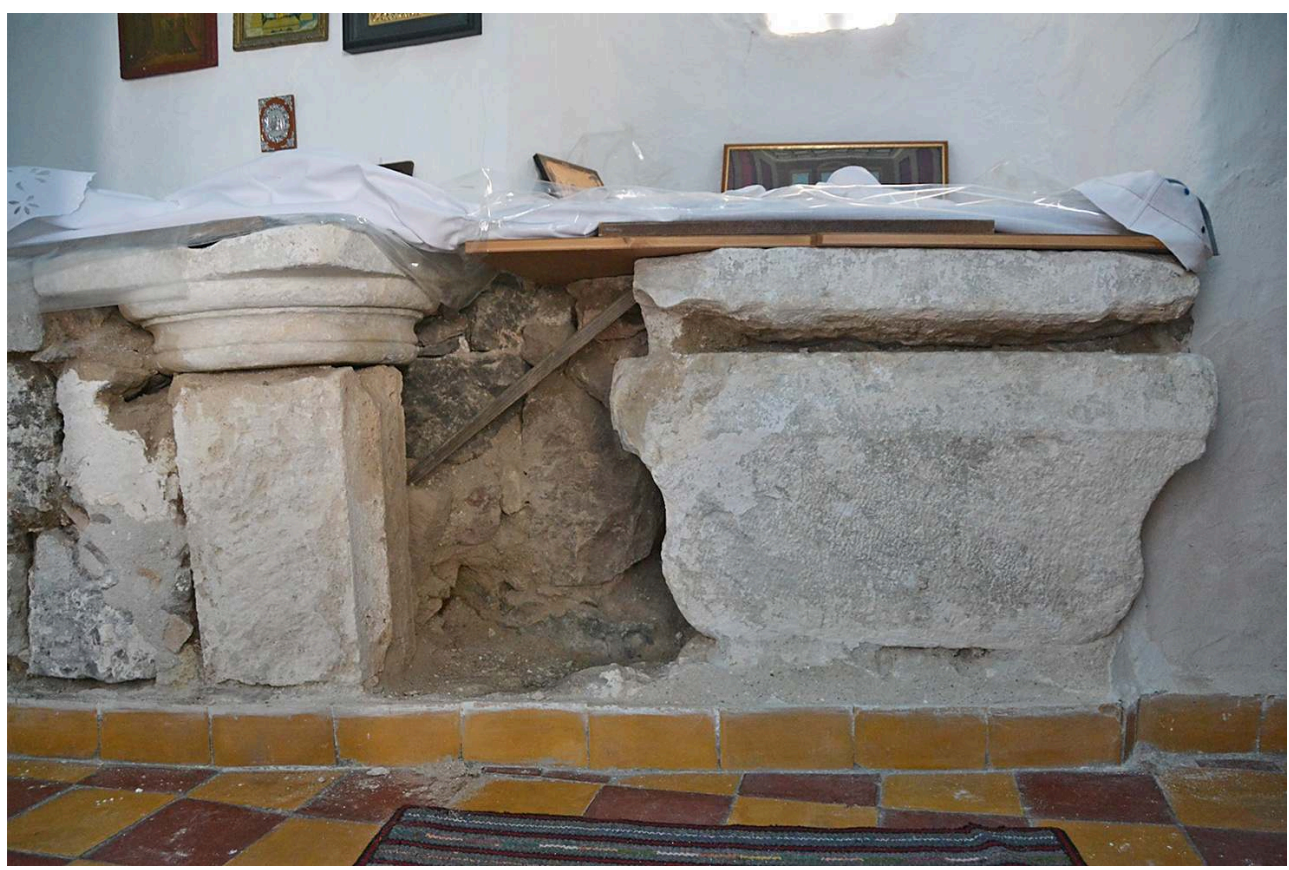

Cliché J.-Ch. Moretti / EFA.

- Un fragment de fût dorique cannelé en poros dont deux faces ont été grossièrement aplanies lors du remploi (inv. 23). Son diamètre a pu être estimé graphiquement à environ $39 \mathrm{~cm}$ aux arêtes. Le fût aurait comporté 16 cannelures si une surface équivalant à deux cannelures n'avait été finement dressée sans doute pour adosser la colonne. Il s'agit du seul bloc en poros identifié sur la colline.

- Une base ionique de type attique en marbre blanc (inv. 24). Cette base ne peut être associée aux éléments d'ordre corinthien en marbre que nous avons reconnus en 2017, mais elle est comparable à deux bases actuellement conservées devant le musée archéologique de Milo à Plaka.

- Un bloc de marbre blanc de plan carré comportant trois faces lisses à doucine et bandeau (inv. 25). La quatrième face, moins finement taillée, n'était sans doute pas visible. Elle présente dans le prolongement du bandeau une zone verticale et dans celle de la doucine une zone plane de même inclinaison que celle-ci. 
INDEX

Thèmes : EFA

lieux https://ark.frantiq.fr/ark:/26678/pcrtunPt0uUWp9

sujets https://ark.frantiq.fr/ark:/26678/pcrts8SiTTY3Ka, https://ark.frantiq.fr/ark:/26678/

pcrtXk6sdvTjnE, https://ark.frantiq.fr/ark:/26678/pcrtxzTYzVBKas, https://ark.frantiq.fr/ark:/ 26678/pcrtSkipOsBGML

chronologie https://ark.frantiq.fr/ark:/26678/pcrtNzYn31IIAZ

Année de l'opération : 2017

\section{AUTEURS}

\section{ALAIN BADIE}

IRAA, CNRS, AMU, LL2, Lyon, UPPA

JEAN-CHARLES MORETTI

IRAA, CNRS, AMU, LL2, Lyon, UPPA 